\title{
Algorithms for Technical Integration of Virtual Power Plants into German System Operation
}

\author{
André Richter*, Ines Hauer, Martin Wolter
}

Otto-von-Guericke University, Institute of Electric Power Systems, Chair Electric Power Systems and Renewable Energy Sources, 39106 Magdeburg, Germany

\begin{tabular}{l} 
A R T I C L E I N F O \\
\hline Article history: \\
Received: 15 November, 2017 \\
Accepted: 20 December, 2017 \\
Online: 30 January, 2018 \\
\hline
\end{tabular}

Keywords:

Virtual Power Plants

Operational concepts

Power system

Renewable Energy Sources

Optimization

Case study

\begin{abstract}
A B S T R A C T
This paper critically evaluates the operational perspective of Virtual Power Plants (VPP) in Germany by analyzing key factors to replace conventional power plants in the future power system. Therefore, its necessity for the secure operation as well as the technical and economic benefits for the German power system are pointed out. The single sections describe in detail how the requirements on technical functions and standardized communication can be reconciled with the increasing challenges on volatile generation. Furthermore, different operation concepts (profit maximization, intra-day schedule loyalty and system services maximization) are described with respect to their mathematical algorithms and their practical feasibility under consideration of given circumstances and future developments. The impact on the power system by the different possible VPPoperational concepts are exemplary pointed out in a case study with use of a medium voltage Cigre-Benchmark Network. The results indicate a high impact on hand-over points by VPP operational concepts.
\end{abstract}

\section{Introduction}

This paper is an extension of work originally presented in 14th International Conference on the European Energy Market (EEM) [1]. The goal of the German government to reduce $\mathrm{CO} 2$ emissions about $40 \%$ until 2020 leads to a rising energy infeed fluctuation evoked by renewable energy sources in the German power system[2]. Due to a high percentage of volatile power infeed, the share of gross electricity generation in 2016 increased to $12.3 \%$ from wind, $7.0 \%$ from bio power plants and $5.9 \%$ from photovoltaic (PV) [3]. The future share of renewable energy sources should rise up much more according to the German government. $45 \%$ of the renewable power was installed in medium and low voltage level [4], so that a large percentage of uncontrolled generation is located in this area. Therefore, the electricity system requires intelligent power networks to secure a stable balance between generation and demand [5]. One part of this intelligent power network is a Virtual Power Plant (VPP) that provides centralized control for aggregated units. The future system shall provide advanced functionalities similar to real power plants aiming on economically sensible generation and increased reliability $[6,7]$. Therefore, the individual functionalities of decentralized units are bundled up using suitable communication and control systems to entirely replace conventional power plants [7]. However, bundling up single functionalities of single

*Corresponding Author: André Richter, Email: andre.richter@ovgu.de

WWw.astesj.com

https://dx.doi.org/10.25046/aj030117 generation unit's does not directly secure similar operation concepts to conventional power plants.

Therefore, this paper deals with the question how VPP can be integrated into the current German power system exploiting their advantageous characteristics like centralized control of small volatile renewable generation units. Included in this, current available technical VPP properties as well as available and economic reasonable operation concepts are checked under consideration of current market circumstances. For example, so far there is no operation concept for VPP that supports the elimination of critical situations in TSO and DSO voltage levels.

[6-8] present some investigations already dealt with corresponding optimization methods for operational concepts, but none of them addresses the overall system requirements in its entirety. For that reason, Figure 1 illustrates the system design of a VPP as well as the interaction of market and power system participants and components. All units are remotely accessible through a central energy management and control center, which calculates the optimal schedule by taking into account information from the electricity market and forecast data of the individual generation and load units.

The overall flexibility of decentralized power units could be improved by applying the concept of VPP's [6, 7, 9] but the German electricity market together with applicable regulations still 


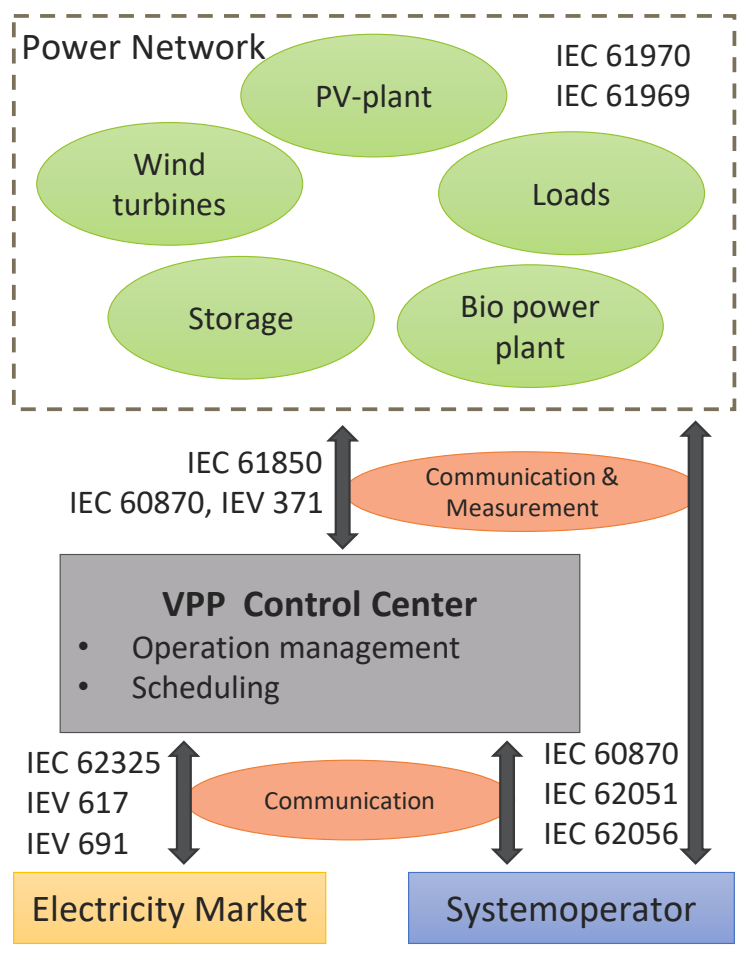

Figure 1. Components of the VPP and influencing factors

not provide the required incentives for a sustainable operation and consequently for a large-scale roll-out. Based on the identification of basic requirements, this paper points out different necessary presupposes for the operation of VPP's similar to conventional power plants. This includes different aspects like communication, generation and demand forecast as well as the German electricity market behavior and costs $(c)$ for generation (Error! Reference source not found.).

Table 1: Costs of renewable generation without investment costs

\begin{tabular}{|l|r|r|}
\hline & \multicolumn{1}{|c|}{$\begin{array}{c}\text { Variable costs in } \\
\boldsymbol{\epsilon} / \mathbf{k W h}\end{array}$} & $\begin{array}{c}\text { Annual fix costs in } \\
\boldsymbol{\epsilon} / \mathbf{k W}\end{array}$ \\
\hline Wind turbines [10] & $0.0241-0.0268$ & $56-61$ \\
\hline PV plants [11,12] & 0.0000 & $13.00-35.00$ \\
\hline Biopower plants [12] & 0.0325 & 175.00 \\
\hline
\end{tabular}

Furthermore, these presupposes are necessary to realize the new VPP operational concepts for taking part in network congestions elimination or control reserve contribution as well as intra-day schedule loyalty concerning the day-ahead planned generation unit operation. Therefore, not only the benefit for VPP owners and direct marketers is identified, but mainly the operational concpets are mathematically described. The paper presents an ongoing case study, where operational concepts are tested and evaluated according to the impact in a medium voltage CIGRE benchmark system. Thereby, the basic preconditions for the operation of Virtual Power Plants according to the German Market system are considered. Finally, the results and conclusion will indicate the high impact of small centralized controlled generation units as well as use cases where only small incentives are needed for the realization of the system supporting technical concpets. This paper differs strongly from the original paper in [1] by an extended definition of market restriction, in detail concerning the control reserve market and by presenting defined operational concepts and algorithms.

\section{Basic Requirements of VPP's}

\subsection{Communication}

Communication is a basic requirement for the operation of VPP as well of intelligent power networks in general. Therefore, it is necessary that generation units, controllable loads and all players offering power flow flexibility and aiming on benefits from variable tariffs can use a standardized and reliable communication system [5]. Based on this, there is a need for a standardized communication language and easy data exchange between all players [13]. Table II lists typical standards for communication in electric power systems, which can be applied in German power system. Furthermore all these standards are necessary for the operation of VPP and the communication with measurement systems, market and the system operator.

Table 2: Communication standards for intelligent power networks [14, 15]

\begin{tabular}{|l|l|}
\hline Standard content & Standard \\
\hline Telecontrol & IEC 60870, IEV 371 \\
\hline $\begin{array}{l}\text { Communication systems in } \\
\text { substations }\end{array}$ & IEC 61850 \\
\hline $\begin{array}{l}\text { Interface for distribution } \\
\text { management }\end{array}$ & IEC 61968 \\
\hline Energy market communication & IEC 62325 \\
\hline $\begin{array}{l}\text { Data exchange with metering } \\
\text { equipment / Electricity Metering }\end{array}$ & IEC 62051 /IEC 62056 \\
\hline $\begin{array}{l}\text { Application in energy management } \\
\text { system }\end{array}$ & IEC 61970 / 61969 \\
\hline
\end{tabular}

Table II shows that various communication standards are applied to VPPs [16, 17]. According to [17] the IEC 61850 represents one of the most important communication standards for the operation and control of VPP with the integrated intelligent networks and distributed units. The innovative standard enables a secure and reliable communication and control using intelligent measurement systems like Phasor Measurement Units (PMUs) and control units like Remote Terminal Units (RTUs) [17 - 19]. Its necessity is based on the requirement to standardize data-models and furthermore to describe communication mechanisms and system management aspects. This standard is an extension to IEC 60870 resulting from adapted power system requirements. IEC 61850 has the advantage of defining data units through logical nodes with defined data structures (common data classes) [20]. The adressed protocol enables the control center to have direct data access and direct control to any physical unit of the VPP in the power network. Furthermore, the application of this standard combined with direct communication supplies the VPP operator with information about the physical location so that he is able to separate physical units according to accounting areas for instance.

\subsection{Forecast-oriented power unit scheduling}

For setting up an optimal power unit schedule, the VPP operator needs to distinguish the individual characteristics of the available resources. This information is not only necessary for an 


\section{A. Richter et al. / Advances in Science, Technology and Engineering Systems Journal Vol. 3, No. 1, $135-147$ (2018)}

optimal market participation, but also for enabling the system operator to make day-ahead and intra-day forecasts as well as to know the maximum controllable power for critical situations. The demand forecast for high numbers of small consumers can be realized using standardized load profiles. Bigger customers, like industry companies with bilateral contracts, require separate measurement systems in order to meet the requirements for providing dedicated demand side potential. In contrast, a larger percentage of units in the VPP are generation units and especially volatile ones like PV plants and wind turbines. Consequently, an exact forecast for those units is indispensable from the operator's point of view, e.g. for scheduling the secondary control reserve [21].

The forecast for wind and PV generation can be realized with different methods presented in Figure 2 and Figure 3. Thereby, the volatile factors are wind speed and solar radiation [19].
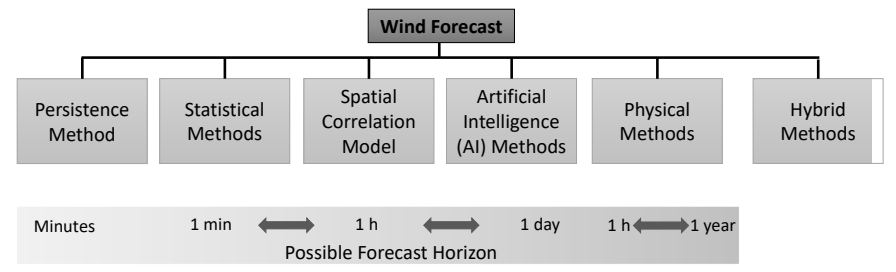

Figure 2. Overview of wind forecast methods and corresponding mathematical algorithms, [21 - 23]
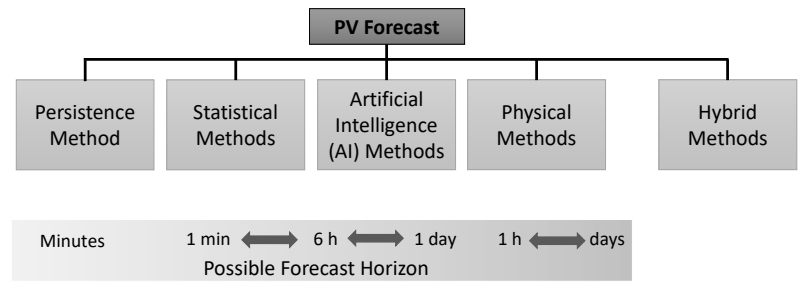

Figure 3. Overview of PV forecast methods and corresponding mathematical algorithms [25]

Wind forecast methods can be divided in six groups depending on its corresponding mathematical algorithms. Four methods (Persistence-, Statistical-, Artificial Intelligence method and Spatial Correlation model) are based on current wind measurement and statistical data as well as on learning approaches to predict wind generation. Depending on the applied method, the forecast horizon varies between a few minutes up to one day. To achieve an increase in accuracy and time horizon, it is necessary to use a physical or hybrid method. Both methods are based on meteorological and climate data and use the numerical weather prediction (NWP) for that purpose, but under the constraint of high computational effort. Regarding the methods and the forecast horizon the best accuracy (mean absolute error) varies between $5 \%$ and $7 \%$ for one to two hours forecast and increases for dayahead forecast [21 - 24]. According to Figure 3, three of the shown methods (Persistence-, Statistical- and Artificial Intelligence Method) process current solar radiation and statistical data. This way utilizable data can be provided for a forecast horizon of a few minutes until one day. However, similar to wind forecast the accuracy rapidly decreases with the forecast horizon. Compared to wind forecast, PV forecast depends even more on the availability of information from weather stations and satellite data to detect clouds, high fog and other phenomena that effect solar radiation. Therefore, the physical method and the hybrid methods use NWP and Cloud Imagery for prediction with subsequent data post processing [25].

In consequence to the described uncertainties in generation forecast, the VPP operator has to deal with different impacts. In case of direct market participation, he has to expect sanctions from the power system operator or to participate in the Intra-Day market accepting possible high costs [26]. Besides using storage systems, there is a solution by using existing flexibilities from wind turbines pv, biomass plants and other technical solutions as in Error! Reference source not found. Those technologies can provide power reserve if they are not operated at their maximum power output limit. However, since storage systems are still expensive and an appropriate market model involving positive and negative power capacity of wind and bio generation is not provided, more profit can be achieved by operating the units at its maximum power output level.

\subsection{German Electricity Market}

In this section, the German electricity market will be characterized focusing on VPP to identify possible operation behavior which influence system operation. Based on this, there are three possibilities to sell energy from renewable energy sources. The first possibility is to receive fixed payment, which is determined based on the German Renewable Energy Act (EEG). The other two possibilities are to participate in the Energy-OnlyMarket and to sell control reserves at the balancing market [26].

The electricity is traded in Germany either at the energy exchange or bilateral at the Over-the-Counter market. The European Energy Exchange (EEX) in Leipzig is the biggest market place for electricity produced in Germany. Electricity on the EEX can be traded either on the futures market or on the spot market (EPEX SPOT in Paris). The main difference between these markets is the electricity delivery time. Thus, the future markets provides contracts for long-term supply of electricity up to six years in the future [26]. The spot market is used as a trading platform for the short-term supply of electricity within 1-2 days, namely Day-Ahead and Intra-Day market $[26,28]$. Thus, the dayahead market is used to trade the electricity, that will be generated and consumed the next day. Because of the fact, that the day-ahead market is based on forecasted profiles (generation and consumption), an Intra-Day market is necessary to balance the forecasted errors. The contracts on the Spot market are mostly carried out physically, that means the physical electricity delivery to the fixed date [29]. According to ( $\$ 11$ EEG 2014), a system operator is obligated to transmit the renewable electricity and to sell it at the exchange. The operators of renewable power plants receive a fixed remuneration, which is supported by the EEGapportionment. As a result, the renewable energy sources are always first at the merit-order, independently of the operation costs. Nuclear and lignite power plants follow, since they are usually used to cover the base load due to technical and economic advantages. Hard coal, gas and oil power plants are usually more expensive. Thus, renewable electricity has a great influence on the electricity price, because of its prior position. The operator of renewable energy sources can freely choose between a fixed EEG remuneration and the direct marketing at the beginning of each calendar year, §20 (1) EEG 2014. In addition, all systems with an installed power of more than $100 \mathrm{~kW}$, which are set to operation from 1 January 2016, must be marketed directly ( $\$ 21$ EEG 2017). The benefit of direct trading in contrast to the fixed remuneration is that trader get the chance of higher profits by receiving market earnings plus a market premium. The market premium is lower 


\section{A. Richter et al. / Advances in Science, Technology and Engineering Systems Journal Vol. 3, No. 1, $135-147$ (2018)}

than the fixed remuneration but another governmental incentive to get a higher percentage of renewables in the market system. However, there are some technical limitations which restrict the operation of VPP at the market and in the power system. These are for example the lowest bid of $0.1 \mathrm{MW}$ to participate in the Dayahead and in the continous Intra-Day market. Furthermore, there are finacial requirements to participate in the spot market, in Germany [30]. The participation fee for Day-ahead market is about $10000 € /$ a with additional $0.04 € / \mathrm{MWh}$ (Day-Ahead auction) and $0.08 € / \mathrm{MWh}$ (intra-day auction). Aditionally, there is a one-time participation fee to get into the spot market of about $25000 €$ for Day-Ahead market. These are costs that have to be covered by an optimal operational concept or new regulatory incentives.

The control reserve market in Germany is characterized by the fact that the German transmission system operator are responsible to keep the power system stable and the rated frequency of $50 \mathrm{~Hz}$. There are 3 types of control reserves (primary control reserve, secondary control reserve as well as minute reserve). These types are differentiated according to activation speed and duration. The procurement of these control reserves is organized in a tender auction with participation of power plant operators and customers. One main fact is that pooling is still permitted to reach the market entry boundaries [31]. Main characteristics of the three control reserves are explained subsequently according to [32]:

Primary control reserve (PCR):

- full activation of PCR within 30 seconds

- incident period that have to be covered $0<\mathrm{t}<15 \mathrm{~min}$

- automatic activation

- symmetrical (positive and negative PCR is not separated) bid of minimum +/- $1 \mathrm{MW}$

- the tender submission period is one week

- fixed power price

Secondary control reserve (SCR):

- $\quad$ energy balance of the control area and frequency control

- immediate automatic activation by the concerned TSO

- complete activation within 5 minutes

- automatic activation based on Merit-Order-List

- $\quad$ separated bid for negative and positive SCR is possible

- $\quad$ separation of SCR positive and negative in high tariff (HT, on Monday till Friday, 8 am til $8 \mathrm{pm}$ ) and low tariff (LT, weekend, national holidays and $8 \mathrm{pm}$ til $8 \mathrm{am})$

- minimum bid of $5 \mathrm{MW}$ and an increment of $1 \mathrm{MW}$

- the tender submission period is one week

- $\quad$ fixed power price and energy price on call

Minute reserve (MR):

- $\quad$ automatic activation is based on a Merit-Order-List

- complete activation within 15 minutes

- incident period that have to be covered are $t>15 \mathrm{~min}$ to 4 quarter hours or up to severalhours in case several incidents

- $\quad$ separated bid for negative and positive MR is possible

- $\quad$ positive and negative MR, always with six 4-hour time slices

- minimum bid of $5 \mathrm{MW}$

- the tender submission period is one day

- $\quad$ fixed power price and energy price on call
Finally, the market regulatories and EEG incentives for the operation of single generation units are nowadays much higher, instead of VPP-operation with centralized controlled of small generation units. But there are ongoing changes in the market system which enable VPP for offering more system supporting functionalities. In [33] a change in the control reserve market system is already anounced. For instance, SCR and MR are intended for a daily (calendar) tender submission period with 4hour time slices. Furthermore, exceptional rules that allow for minimum bids below $5 \mathrm{MW}$ are introduced.

In conclusion, there are still no high financial and regulatory incentives to operate VPP in a way, which serves both areas market and technical operation - at the moment. Because of this physical delivery of electricity remains uncertain with respect to a future power system including a higher share of renewables. Consequently, it will be indispensable to use the VPP benefits of generation unit aggregation and its aggregated central controlled flexibilities to have minimum system effecting controllable power. Therefore, some assumptions are made for the ongoing analyzes for a medium-term future VPP.

\section{VPP-Operational concepts}

One of the main challenges of VPP operators is the setup of the internal merit order, that defines which power unit shall be used to satisfy a certain power demand or infeed. This has to be done under consideration of type of generation unit, its technical capability and regulatory as well as economical restrictions. However, right now VPP operators maximize their profits by offering as much energy as possible in the markets aiming on the highest possible profit. As one result, VPP functionalities remain unused due to missing monetary or regulatory incentives, in particular the centralized control of aggregated small generation units. This causes a problem for the system operator: VPP operators sell energy based on the market premium at every point of time, even in case of congestions in the DSO or TSO network.

Therefore, this paper offers two main system supporting operational concepts and additonally an economical concept (see Figure 4). Each concept is explained in detail in the ongoing subsections 3.2 and 3.3.

1) Economical oriented (green): porift maximization, by optimal energy selling on the electricity market.

2) Technical oriented (orange): intra-day schedule loyalty and system service maximization including centriole reserve maximization and redispatch maximization.

\subsection{Mathematical optimization problem}

The operational concepts can be mathematically involved and expressed in terms of a maximization or minimization problem (objective function) with a given number of restricted goods (constraints). Therefore, this paper presents options to solve the optimization problems in MATLAB for day-ahead scheduling and intra-day schedule loyalty in intervals of 15 minutes. The development of schedules in day-ahead and intra-day planning rely on an optimization problem with an application-specific objective function. The restrictions are defined for technical characteristics of the system, electricity market restrictions and for current as well as predicted system states. Linear optimization method based on simplex algorithm is applied to solve the optimization problem. Linear optimization either minimizes or maximizes a linear 


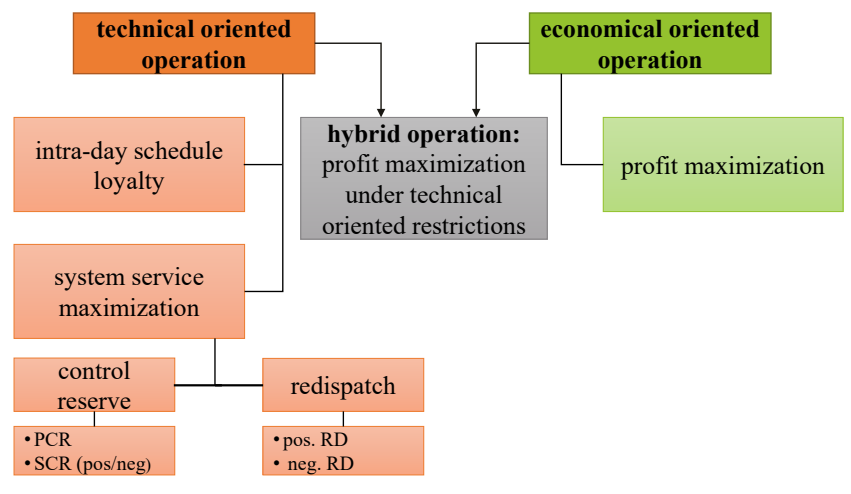

Figure 4. VPP operational concepts

objective function, taking into account linear constraints. The linear optimization contains only continuous variables, whereby benefitery short calculation times are realized. From the linear optimization, the mixed integer linear optimization can be distinguished. Mixed integer linear optimization (MILP) is the basis of the optimization problem for day-ahead and intraday optimization implemented in this paper. Unlike linear optimization, variables can be either continuous or integer or binary. Especially with binary variables it is possible to model logical conditions. The degree of detail of the optimization can be increased, but this is accompanied by an increase in the computational effort for the determination of the optimal solution. [34] The solver intlinprog is used to implement the scheduling problem in MATLAB. Firstly, the objective function is defined and implemented according profit maximization. Ongoing the different technical and economical upper and lower bounds as well as linear constraints were defined and implemented. Finally, the integer constraints have to be implemented. The solver finds a first less constraint starting solution by using linear optimization without integer constraints. The starting solution serves as a starting point for new solutions for the method branch and bound. The method branch and bound takes all constraints and inequaltities into account by generating subproblems and finally finds the best solution, if this solution is within a defined tolerance gap according to the other solutions.

\subsection{Economical oriented operation}

The main objective of a power plant operator and thus a VPP operator is always to maximize its profits, regardless of the system situation. The regulatory framework and the optimization skills always determine whether or in what amount the operator generates profit. Consequently, the composition of the VPP has a significant impact on potential profits. In the analysis of this concept for resource planning, an optimization based on today's market data for control reserve markets ( $\left.p_{\mathrm{PCR} / \mathrm{SCR} / \mathrm{MR}} / P_{\mathrm{PCR} / \mathrm{SCR} / \mathrm{MR}} \quad\right), \quad$ Day-Ahead auction $\left(p_{\text {auction }} / P_{\text {wind/pv/bio,auc }}\right)$ and continuous Intra-Day market ( $\left.p_{\text {continous,IH,T }} / P_{\text {wind/pv/bio,continous,IH,T }}\right)$ is made. The analysis assumes that both a fixed EEG allowance and a market premium for market participation through EEG plants are not paid out. Aim of this assumption is to analyze the VPP operation under perfect market conditions without any subsidies. This leads to the objective function where profit $(p)$ should be maximized by optimal day-ahead generation unit schedule $\left(P_{\text {wind }}, P_{\mathrm{pv}}\right.$ and $\left.P_{\text {bio }}\right)$. The optimal distribution of power to different selling options is www.astesj.com limited to the forecast of renewables ( $\left.P_{\mathrm{wind} / \mathrm{pv} \text {, forecast }}\right)$, the installed power, various constraints and other secondary conditions which are described in (2) - (34).

$$
\begin{aligned}
\max f(p)= & p_{\text {wind }}(t) \cdot P_{\text {wind }}(t)+p_{\mathrm{pv}}(t) \cdot P_{\mathrm{pv}}(t) \\
& +p_{\mathrm{bio}}(t) \cdot P_{\mathrm{bio}}(t) \\
& +p_{\text {auction }}(t) \cdot P_{\mathrm{wind}, \mathrm{auc}}(t) \\
& +p_{\text {auction }}(t) \cdot P_{\mathrm{pv}, \mathrm{auc}}(t) \\
& +p_{\text {auction }}(t) \cdot P_{\mathrm{bio}, \mathrm{auc}}(t) \\
& +p_{\text {continous,IH,T }}(t) \cdot P_{\mathrm{wind}, \mathrm{continous}, \mathrm{IH}, \mathrm{T}}(t) \\
& +p_{\text {continous,IH,T }}(t) \cdot P_{\mathrm{pv}, \mathrm{continous}, \mathrm{IH}, \mathrm{T}}(t) \\
& +p_{\text {continous, } \mathrm{IH}, \mathrm{T}}(t) \cdot P_{\mathrm{bio}, \mathrm{continous}, \mathrm{IH}, \mathrm{T}}(t) \\
& +p_{\mathrm{PCR}}(t) \cdot P_{\mathrm{PCR}}(t) \\
& +p_{\mathrm{SCR}, \mathrm{pos}}(t) \cdot P_{\mathrm{SCR}, \mathrm{pos}}(t) \\
& +p_{\mathrm{SCR}, \text { neg }}(t) \cdot P_{\mathrm{SCR}, \text { neg }}(t) \\
& +p_{\mathrm{MCR}, \mathrm{pos}}(t) \cdot P_{\mathrm{MCR}, \mathrm{pos}}(t) \\
& +p_{\mathrm{MCR}, \text { neg }}(t) \cdot P_{\mathrm{MCR}, \text { neg }}(t)
\end{aligned}
$$

During the analyzes several constraints are considered. The main constraints are:

- The profit calculation based on revenue $(r)$ is depending on the market selling option and the costs $(c)$ (energy generation costs, spot-market selling).

$$
\begin{gathered}
p_{\text {wind }}(t)=-c_{\text {wind }} \\
p_{\mathrm{pv}}(t)=-c_{\mathrm{pv}} \\
p_{\text {bio }}(t)=-c_{\text {bio }} \\
p_{\text {auction }}(t)=r_{\text {auction }}(t)-c_{\text {auction }} \\
p_{\text {continous.IH,T }}(t)=r_{\text {continous.IH,T }}(t)-c_{\text {continous.IH }}
\end{gathered}
$$

- Minimum possible generation for wind, PV and bio generation that can be used for optimization: The factors $f_{\text {wind,min }} f_{\mathrm{pv}, \text { min }}$ and $f_{\text {bio,min }}$ set the lower bounds of minimum generation output. They define pre-process depending generation output especially for bio generation. The minimum for wind and $\mathrm{PV}$ is zero by default.

$$
\begin{gathered}
f_{\text {wind,min }} \cdot P_{\text {wind,forecast }}(t) \leq P_{\text {wind }}(t) \\
f_{\mathrm{pv}, \min } \cdot P_{\mathrm{pv}, \text { forecast }}(t) \leq P_{\mathrm{pv}}(t) \\
f_{\mathrm{bio,min}} \cdot P_{\text {bio,inst }} \leq P_{\mathrm{bio}}(t)
\end{gathered}
$$

- Bio generation power ramping: The maximum rate of change of power ( $\left.f_{\triangle P \text { bio,pos }}, f_{\triangle P \text { bio,neg }}\right)$ is limited, comparable with conventional power plants. 
increase of power for $\mathrm{t}=1$ :

$$
P_{\text {bio }}(t)-f_{\text {bio, Start }} \cdot P_{\text {bio,inst }} \leq f_{\Delta \text { Pbio, pos }} \cdot P_{\text {bio,inst }}
$$

increase of power for $\mathrm{t} \geq 2$ :

$$
P_{\text {bio }}(t)-P_{\text {bio }}(t-1) \leq f_{\Delta \text { Pbio,pos }} \cdot P_{\text {bio,inst }}
$$

decrease of power for $\mathrm{t}=1$ :

$$
f_{\text {bio,Start }} \cdot P_{\text {bio,inst }}-P_{\text {bio }}(t) \leq f_{\Delta \text { Pbio,neg }} \cdot P_{\text {bio,inst }}
$$

decrease of power for $\mathrm{t} \geq 2$ :

$$
P_{\text {bio }}(t-1)-P_{\text {bio }}(t)-\leq f_{\Delta P \text { bio,neg }} \cdot P_{\text {bio,inst }}
$$

- Limitation of provision of control reserve (CR) by bio generation: Not every bio power plant is able to fulfill the technical requirements of PCR provision. Therefore, the proportion of bio generation units that can provide PCR can be limited with the factor $f_{\mathrm{Bio}, \mathrm{PCR}}$. Furthermore, the contribution of PCR and SCR has to be defined in constraints according to the technical requirements that PCR have to be provided in at least $30 \mathrm{~s}$ and SCR in at least 5 min. $f_{\mathrm{d} P \text { bio,pos }}$ and $f_{\mathrm{dPbioneg}}$ describe the maximum possible rate of change of power in one minute so that the constraints for PCR and SCR are described as follows:

PCR contribution within $30 \mathrm{~s}$, positiv and negative:

$$
\begin{aligned}
& \mathrm{d} P_{\text {bio,PCR,pos }}(t) \leq \frac{f_{\mathrm{d} P \text { bio,pos }}}{2} \cdot f_{\text {bio,PCR }} \cdot P_{\text {bio,inst }} \\
& \mathrm{d} P_{\text {bio,PCR,neg }}(t) \leq \frac{f_{\mathrm{d} P \text { bio,neg }}}{2} \cdot f_{\text {bio,PCR }} \cdot P_{\text {bio,inst }}
\end{aligned}
$$

SCR contribution within $5 \mathrm{~min}$, positiv and negative:

$$
\begin{aligned}
& \mathrm{d} P_{\text {bio,SCR,pos }}(t) \leq 5 \cdot f_{\mathrm{d} P \text { bio,Pos }} \cdot P_{\text {bio,inst }} \\
& \mathrm{d} P_{\text {bio,SCR,neg }}(t) \leq 5 \cdot f_{\mathrm{d} P \text { bio,neg }} \cdot P_{\text {bio,inst }}
\end{aligned}
$$

- Maximum possible control reserve. The provision of control reserve is limited to the requirements described in section 2.3. These are the continuous availability of CR according to the defined periods (PCR-continuous over the day, SCR-LT, SCR-HT, MR-4 hour intervals) and under consideration of wind and PV forecast and the limited contribution of bio generation, respectively.

PCR positive and negative:

$$
\begin{gathered}
P_{\mathrm{PCR}}(t) \leq P_{\text {wind,forecast }}(t)-P_{\text {wind }}(t) \\
+P_{\mathrm{pv}, \text { forecast }}(t)-P_{\mathrm{pv}}(t) \\
+\mathrm{d} P_{\mathrm{bio}, \mathrm{PCR}, \mathrm{pos}}(t) \\
P_{\mathrm{PCR}}(t) \leq P_{\text {wind }}(t)-f_{\text {wind,min }} \cdot P_{\text {wind,forecast }}(t) \\
+P_{\mathrm{pv}}(t)-f_{\mathrm{pv}, \text { min }} \cdot P_{\mathrm{pv}, \text { forecast }}(t) \\
+\mathrm{d} P_{\text {bio,PCR,neg }}(t)
\end{gathered}
$$

SCR positive and negative:

$$
\begin{aligned}
P_{\mathrm{SCR}, \mathrm{pos}, \mathrm{HT}}(t)+P_{\mathrm{SCR}, \mathrm{pos}, \mathrm{NT}}(t) & \leq P_{\text {wind,forecast }}(t)-P_{\text {wind }}(t) \\
& +P_{\mathrm{pv}, \text { forecast }}(t)-P_{\mathrm{pv}}(t) \\
& +\mathrm{d} P_{\text {bio, } \mathrm{SCR}, \mathrm{pos}}(t) \\
P_{\mathrm{SCR}, \text { neg, } \mathrm{HT}}(t)+P_{\mathrm{SCR}, \text { neg, } \mathrm{NT}}(t) & \leq P_{\mathrm{wind}}(t) \\
& -f_{\text {wind,min }} \cdot P_{\text {wind,forecast }}(t) \\
& +P_{\mathrm{pv}}(t) \\
& -f_{\mathrm{pv}, \text { min }} \cdot P_{\mathrm{pv}, \text { forecast }}(t) \\
& +d P_{\mathrm{bio}, \mathrm{SCR}, \text { neg }}(t)
\end{aligned}
$$

MR positive and negative:

$$
\begin{gathered}
P_{\mathrm{MCR}}(t) \leq P_{\text {wind,forecast }}(t)-P_{\mathrm{wind}}(t) \\
+P_{\mathrm{pv}, \text { forecast }}(t)-P_{\mathrm{pv}}(t) \\
+P_{\mathrm{bio}, \text { inst }}-P_{\mathrm{bio}}(t) \\
P_{\mathrm{MCR}}(t) \leq P_{\mathrm{wind}}(t)-f_{\mathrm{wind}, \min } \cdot P_{\mathrm{wind}, \text { forecast }}(t) \\
+P_{\mathrm{pv}}(t)-f_{\mathrm{pv}, \text { min }} \cdot P_{\mathrm{pv}, \text { forecast }}(t) \\
+P_{\mathrm{bio}}(t)-f_{\mathrm{bio}, \min } \cdot P_{\mathrm{bio}, \text { inst }}
\end{gathered}
$$

- Avoidance of multiple use of power for control reserve provision: This constraint defines an upper limit for the sum of CR not exceeding the amount of available power. This is divided into positive and negative $\mathrm{CR}$.

$$
\begin{aligned}
& C R_{\mathrm{pos}}(t)=P_{\mathrm{PCR}}(t)+P_{\mathrm{SCR}, \mathrm{pos}, \mathrm{HT}}(t) \\
& +P_{\mathrm{SCR}, \mathrm{pos}, \mathrm{NT}}(t)+P_{\mathrm{MR}, \text { pos }, 4 \text { h-slice }}(t) \\
& C R_{\text {pos }}(t) \leq P_{\text {wind,forecast }}(t)-P_{\text {wind }}(t) \\
& +P_{\mathrm{pv}, \text { forecast }}(t)-P_{\mathrm{pv}}(t) \\
& +\mathrm{d} P_{\text {bio,PCR,pos }}(t) \\
& C R_{\text {pos }}(t) \leq P_{\text {wind,forecast }}(t)-P_{\text {wind }}(t) \\
& +P_{\mathrm{pv}, \text { forecast }}(t)-P_{\mathrm{pv}}(t) \\
& +P_{\text {bio,inst }}-P_{\text {bio }}(t) \\
& C R_{\text {neg }}(t)=P_{\mathrm{PCR}}(t)+P_{\mathrm{SCR}, \text { neg, } \mathrm{HT}}(t) \\
& +P_{\mathrm{SCR}, \text { neg,NT }}(t)+P_{\mathrm{MR}, \text { neg, } 4 \text { h-slice }}(t) \\
& C R_{\text {neg }}(t) \leq P_{\text {wind }}(t)-f_{\text {wind,min }} \cdot P_{\text {wind,forecast }}(t) \\
& +P_{\mathrm{pv}}(t)-f_{\mathrm{pv}, \min } \cdot P_{\mathrm{pv}, \text { forecast }}(t) \\
& +\mathrm{d} P_{\text {bio,SCR,neg }}(t) \\
& C R_{\text {neg }}(t) \leq P_{\text {wind }}(t)-f_{\text {wind,min }} \cdot P_{\text {wind,forecast }}(t) \\
& +P_{\mathrm{pv}}(t)-f_{\mathrm{pv}, \min } \cdot P_{\mathrm{pv}, \text { forecast }}(t) \\
& +P_{\text {bio }}(t)-f_{\text {bio,min }} \cdot P_{\text {bio,inst }}
\end{aligned}
$$

- Minimum bid and increment for control reserve provision, according to the market restrictions: The control reserve amount can be zero or or an integer 
multiple of the increments, depending on size of minimum bid and minimum increment. The restriction is presented for PCR with analog constraints for SCR and MR. The factor $y(t)$ is a binary variable for the proof, if enough power is available for CR provision.

$$
P_{\mathrm{PCR}}(t)-y_{\mathrm{PCR}}(t) \cdot P_{\mathrm{PCR}, \min } \geq 0
$$

- Spot-market restriction: According to the spot-market options regarded in this paper, there are the possibilities to sell the energy in the Day-Ahead auction offered by hour or in the continuous Intra-Day market offered by 15 minutes. Because of the fact that this is a day-ahead planning process, Intra-Day market prices have to be assumed as forecasted values. A further constraint is that the available energy should be sold out under profitable conditions.

$$
\begin{aligned}
& P_{\text {wind }}(t)=P_{\text {wind,auc }}(t)+P_{\text {wind,continous, } \mathrm{IH}, \mathrm{T}}(t) \\
& P_{\mathrm{pv}}(t)=P_{\mathrm{pv}, \mathrm{auc}}(t)+P_{\mathrm{pv}, \text { continous, } \mathrm{IH}, \mathrm{T}}(t) \\
& P_{\text {bio }}(t)=P_{\text {bio,auc }}(t)+P_{\text {bio,continous, }, \mathrm{HH}, \mathrm{T}}(t) \\
& P_{\text {wind }}(t)+P_{\mathrm{pv}}(t)+P_{\text {bio }}(t) \\
& =P_{\text {wind,auc }}(t)+P_{\text {wind,continous, } \mathrm{IH}, \mathrm{T}}(t) \\
& +P_{\mathrm{pv}, \text { auc }}(t)+P_{\mathrm{pv}, \text { continous }, \mathrm{IH}, \mathrm{T}}(t) \\
& +P_{\text {bio,auc }}(t)+P_{\text {bio,continous, } \mathrm{IH}, \mathrm{T}}(t)
\end{aligned}
$$

As a result of the economic optimization schedules are defined for wind, PV and bio generation. All presented constraints consider the figures presented in section 2. This methodology allows for an economically optimal day-ahead schedule, regardless of the size of the VPP (available generation units) and the impact on the electrical power system. In future systems with high penetration of RES, this can lead to unstabelizing effects and to a lack of system services. Therefore, the system itself and system operator need system supporting services to handle exemplary high volatility generation and forecast errors.

\subsection{Technical oriented operation}

Within this section, various new network-relevant VPP operating concepts are to be examined, which are intended to ensure stable grid operation in the future and also to minimize the effort of operational management for directly and indirectly connected grid operators. These different concepts thus represent the integration of network operator requirements into the operational planning. The new technical concepts meet the request of reliable schedules contributed by VPP and by renewable generation units in general. Furthermore, the presented concepts will enable a maximum of PCR and SCR contribution as well as redispatch. Therefore, the day-ahead maximization function in (1) with its constraints in (2) - (34) are applied. Changed or added objective functions and constraints for optimal day-Ahead scheduling will be presented according to the concepts. The intraday schedule loyalty represents a further concept which was presented in general in [35].

\subsubsection{Intra-day schedule loyalty}

The objective of intra-day schedule loyalty is to minimize the schedule deviation, which is mainly based on forecasting errors related to renewable energy source (RES) infeed in the operational planning of the VPP control center. In this case, the power consumption or the power recovery from or into the higher-level network should be reduced, so that the higher-level network operator or the accounting area manager only has to make few or no interventions. If all VPP operators were capable of doing this in the future, day-ahead planning process of system operators can be optimized and network congestions may be avoided.

However, this requires a defined level of flexibility within the VPP and can also lead to curtailments of generation units. The intra-day loyalty operation must be preceded by a day-ahead optimization in which capacities are blocked in order to compensate intra-day schedule deviations. The consumption of control energy should be avoided, if possible. For this purpose, a high fictitious penalty of $1000 € / \mathrm{MW}$ is initially assumed for the balancing energy consumption when positive balancing power $\left(p_{\text {reBAP,pos }}(t)\right)$ or negative balancing power $\left(p_{\text {reBAP,pos }}(t)\right)$ is consumed. If the day-ahead schedule can not be met without consumption of balancing energy, balancing energy can be received $\left(P_{\text {reBAP,pos }}(t)\right.$ and $\left.P_{\text {reBAP,neg }}(t)\right)$. Therefore, the term of the balancing energy represents a measure of the deviation from schedule. Thereby, a main constraint is that a control reserve deviation ( $P_{\text {deviation,CR,pos }}(t)$ and $\left.P_{\text {deviation,CR,neg }}(t)\right)$ is prohibited by use of fictitious penalty ( $p_{\text {deviation,CR }}$ ) about $10000 € / \mathrm{MW}$. The objective function is presented in (35) with the objective to minimize the deviation according to the planned market schedule.

$$
\begin{aligned}
\max f(p, P) & =p_{\text {wind,intraday }}(t) \cdot P_{\text {wind,intraday }}(t) \\
& +p_{\text {pv,intraday }}(t) \cdot P_{\mathrm{pv, \text {intraday }}}(t) \\
& +p_{\text {bio,intraday }}(t) \cdot P_{\text {bio,intraday }}(t) \\
& +p_{\text {reBAP,pos }}(t) \cdot P_{\text {reBAP,pos }}(t) \\
& +p_{\text {reBAP,neg }}(t) \cdot P_{\text {reBAP,neg }}(t) \\
& +p_{\text {deviation,CR }} \cdot P_{\text {deviation,CR,pos }}(t) \\
& +p_{\text {deviation,CR }} \cdot P_{\text {deviation,CR,neg }}(t)
\end{aligned}
$$

This operational concept requires similar constraints, like fictitious penalties for $\mathrm{CR}$ deviation and the possible use of balancing power. But the most important point for this operational concept is the flexibility, which is used to fulfill the schedule. Therefore, it is needed to reduce the maximum available power output from bio-generation in the day-ahead planning process by a defined value (e.g. $5 \%$ ). This procedure has to be applied for wind and PV forecast as well. The day-ahead forecast has to be reduced by a factor to ensure intra-day flexibilities and intra-day schedule loyalty. The factor has to be optimized depending on forecast precision and VPP generation unit composition. Two further constraints are loyalty of generation units and observance of dayahead and intra-day schedule. The constraint loyalty of generation units has the aim to consider optimized day-ahead generation unit schedules for wind, PV and bio under the changed intra-day 
conditions for renewable infeed $\left(P_{\text {wind,intraday }}(t)\right.$ and $P_{\mathrm{pv}, \text { intraday }}(t)$ ). If this will not be possible, energy has to be bought according to positive balancing power $\left(P_{\text {reBAP,pos }}(t)\right)$ or negative balancing power $\left(P_{\text {reBAP,pos }}(t)\right)$. The constraint observance of day-ahead and intra-day schedule ensure that the schedules of generation units can be changed according to the failure in forecast of renewables. But the sum of generation and the planned amount of cumulated power in each time step for trading on Day-Ahead and Intra-Day market is as much as possible prohibited to change. Both constraints can be expressed as:

$$
\begin{aligned}
P_{\text {wind }}(t)+P_{\mathrm{pv}}(t)+P_{\mathrm{bio}}(t) & =P_{\mathrm{wind}, \text { intraday }}(t) \\
& +P_{\mathrm{pv}, \text { intraday }}(t) \\
& +P_{\text {bio,intraday }}(t) \\
& +P_{\text {reBAP,pos }}(t)-P_{\text {reBAP,neg }}(t)
\end{aligned}
$$

The result of this operational concept is a reliable schedule planning which supports system operator in systems with a high amount of RES to keep a stable system and avoid redispatch. The changed generation unit schedule depends on the quality of forecast and reserved capacity for intra-day flexibility and thus indirectly depending on the quality of the forecast.

Furthermore, this concept only needs small monetary or regulatory incentives, because the needed flexibility reserve not leads to high loss in profit. But there is a need of incentives for this operational concept.

\subsubsection{Redispatch maximization}

The concept of redispatch maximization is a mainly technical triggered concept, which currently has no regulatory or monetary incentives. But in medium-term and future systems there will be an incredible high need for system operators to handle congestions in a system with less controllable conventional power plants. VPP can provide those functions utilizing the concept of centralized control of RES. It has to be assumend that the VPP is either small, so that it feed in a defined network section like in one medium voltage network, or that the schedule for this concept is adaptable for defined network sections. This assumption has to be done to ensure the effectiveness of redispatch in the system. The objective function (37) is focused on the maximization of negative ( $\left.P_{\mathrm{RD} \text {,neg }}(t)\right)$ or positive $\left(P_{\mathrm{RD} \text {,pos }}(t)\right)$ available power for redispatch.

Therefore, the monetary objective function (1) is extended with fictious positive $\left(p_{\mathrm{RD} \text {,pos }}(t)\right)$ and negative $\left(p_{\mathrm{RD} \text {,neg }}(t)\right)$ profit for redispatch. This profit has to be given a high constant value only. A benefit of the methodology of fictious profits to maximize technical needs is that minimum monetary incentives can be identified under given market circumstances, if there is an ambition to create and examine new market concepts for technical needs.

With the integration of redispatch, additional constraints have to be defined. These are the definition of lower bounds for available power, exceeding a defined minimum in (38) - (39) and the calculation of available power for redispatch in (40) - (41).

$$
\begin{aligned}
\max f\left(P_{\mathrm{RD}}\right) & =p_{\mathrm{Wind}}(t) \cdot P_{\mathrm{Wind}}(t)+p_{\mathrm{PV}}(t) \cdot P_{\mathrm{PV}}(t) \\
& +p_{\mathrm{Bio}}(t) \cdot P_{\mathrm{Bio}}(t) \\
& +p_{\text {auction }}(t) \cdot P_{\mathrm{Wind}, \mathrm{auc}}(t) \\
& +p_{\text {auction }}(t) \cdot P_{\mathrm{PV}, \mathrm{auc}}(t) \\
& +p_{\text {auction }}(t) \cdot P_{\mathrm{Bio}, \text { auc }}(t) \\
& +p_{\text {continous }, \mathrm{IH}, \mathrm{T}}(t) \cdot P_{\mathrm{Wind}, \mathrm{continous}, \mathrm{IH}, \mathrm{T}}(t) \\
& +p_{\text {continous }, \mathrm{IH}, \mathrm{T}}(t) \cdot P_{\mathrm{PV}, \mathrm{continous}, \mathrm{IH}, \mathrm{T}}(t) \\
& +p_{\mathrm{continous}, \mathrm{IH}, \mathrm{T}}(t) \cdot P_{\mathrm{Bio}, \mathrm{continous}, \mathrm{IH}, \mathrm{T}}(t) \\
& +p_{\mathrm{PCR}}(t) \cdot P_{\mathrm{PCR}}(t) \\
& +p_{\mathrm{SCR}, \mathrm{pos}}(t) \cdot P_{\mathrm{SCR}, \mathrm{pos}}(t) \\
& +p_{\mathrm{SCR}, \text { neg }}(t) \cdot P_{\mathrm{SCR}, \text { neg }}(t) \\
& +p_{\mathrm{MCR}, \mathrm{pos}}(t) \cdot P_{\mathrm{MCR}, \mathrm{pos}}(t) \\
& +p_{\mathrm{MCR}, \text { neg }}(t) \cdot P_{\mathrm{MCR}, \text { neg }}(t) \\
& +p_{\mathrm{RD}, \mathrm{pos}}(t) \cdot P_{\mathrm{RD}, \mathrm{pos}}(t) \\
& +p_{\mathrm{RD}, \text { neg }}(t) \cdot P_{\mathrm{RD}, \text { neg }}(t)
\end{aligned}
$$

$$
\begin{gathered}
P_{\mathrm{RD}, \text { pos }}(t) \geq P_{\text {min,RD,pos }}(t) \\
P_{\mathrm{RD}, \text { neg }}(t) \geq P_{\text {min, RD, neg }}(t) \\
P_{\mathrm{RD}, \text { pos }}(t)=P_{\text {wind,forecast }}(t)-P_{\text {wind }}(t) \\
+P_{\mathrm{pv}, \text { forecast }}(t)-P_{\mathrm{pv}}(t) \\
+P_{\mathrm{bio}, \text { inst }}-P_{\mathrm{bio}}(t) \\
P_{\mathrm{RD}, \text { neg }}(t)=P_{\text {wind }}(t)+P_{\mathrm{pv}}(t) \\
+P_{\mathrm{bio}}(t)-f_{\mathrm{bio}, \text { min }} \cdot P_{\mathrm{bio}, \text { inst }}
\end{gathered}
$$

\subsubsection{Control reserve maximization}

Control reserve is one of the most needed products in systems with high volatile generation. $\mathrm{CR}$ is important for a global point of view for systems with increased percentage of renewables and decreased number of CR providing conventional power plants. VPP offers the possibility to fulfill market restriction for control reserve market by pooling small decentralized generation units. Depending on the size (amount of installed renewable capacity), VPP can provide only CR products most of the time. Therefore, this optimization maximizes the contribution of positive or negative SCR or the contribution of PCR. The only limiting factors are market restriction concerning minimum bid size and minimum increment, so that $\mathrm{CR}$ is maximized first and remaining energy is traded according to profit maximization. This optimization is again based on (1) extended by fictitious high profit for CR. The fictitious profit is chosen very high, depending on the maximization problem (PCR, pos. SCR and neg. SCR). 


$$
\begin{aligned}
\max f\left(P_{\mathrm{CR}}\right)= & p_{\mathrm{Wind}}(t) \cdot P_{\mathrm{Wind}}(t)+p_{\mathrm{PV}}(t) \cdot P_{\mathrm{PV}}(t) \\
& +p_{\mathrm{Bio}}(t) \cdot P_{\mathrm{Bio}}(t) \\
& +p_{\text {auction }}(t) \cdot P_{\mathrm{Wind}, \mathrm{auc}}(t) \\
& +p_{\text {auction }}(t) \cdot P_{\mathrm{PV}, \text { auc }}(t) \\
& +p_{\text {auction }}(t) \cdot P_{\mathrm{Bio}, \text { auc }}(t) \\
& +p_{\text {continous,IH,T }}(t) \cdot P_{\mathrm{Wind}, \text { continous,IH,T }}(t) \\
& +p_{\text {continous,IH,T }}(t) \cdot P_{\mathrm{PV}, \text { continous,IH,T }}(t) \\
& +p_{\text {continous,IH,T }}(t) \cdot P_{\mathrm{Bio}, \text { continous,IH,T }}(t) \\
& +p_{\mathrm{PCR}}(t) \cdot P_{\mathrm{PCR}}(t) \\
& +p_{\mathrm{SCR}, \mathrm{pos}}(t) \cdot P_{\mathrm{SCR}, \text { pos }}(t) \\
& +p_{\mathrm{SCR}, \text { neg }}(t) \cdot P_{\mathrm{SCR}, \text { neg }}(t) \\
& +p_{\mathrm{MCR}, \text { pos }}(t) \cdot P_{\mathrm{MCR}, \text { pos }}(t) \\
& +p_{\mathrm{MCR}, \text { neg }}(t) \cdot P_{\mathrm{MCR}, \text { neg }}(t)
\end{aligned}
$$

The only constraints which have to be added according to the day-ahead optimization are the definition of lower bounds $\left(P_{\min }\right)$ for minimum provision of control reserve. Further restrictions are still defined in section 3.2. The constraints are:

$$
\begin{aligned}
& P_{\mathrm{PCR}}(t) \geq P_{\min , \mathrm{PCR}} \\
& P_{\mathrm{SCR}, \mathrm{pos}, \mathrm{HT}}(t) \geq P_{\mathrm{min}, \mathrm{SCR}, \mathrm{pos}, \mathrm{HT}} \\
& P_{\mathrm{SCR}, \mathrm{pos}, \mathrm{NT}}(t) \geq P_{\mathrm{min}, \mathrm{SCR}, \mathrm{pos}, \mathrm{NT}} \\
& P_{\mathrm{SCR}, \text { neg, } \mathrm{HT}}(t) \geq P_{\text {min,SCR,neg,HT }} \\
& P_{\mathrm{SCR}, \text { neg, }, \mathrm{NT}}(t) \geq P_{\text {min,SCR,neg, NT }}
\end{aligned}
$$

The result of the control reserve maximization is a scheduling concept to provide system services and enables the transmission system operator to have stable and effective control. Furthermore, if the VPP is located in lower voltage levels, this concept supports the appropriate connection system operator with defined schedule information concerning possible control reserve activation for distribution system operator. This is a necessary information during the day-ahead planning process in case of expected congestions in the distribution system.

\section{Case Study}

The case study demonstrates the application of the presented concepts under consideration of a test network. The impact of the operational concepts on the power system are highlighted according to the case study. The test nework in Figure 6 is based on the CIGRE Benchmark System. The used medium voltage network represents areas of central city, suburb and country grid according to [36-39]. Furthermore, there is only a single handover point to the overlay $110 \mathrm{kV}$ network. Renewable generation from PV, wind and bio mass are collected in the voltage levels $\mathrm{HV} / \mathrm{MV}, \mathrm{MV}, \mathrm{MV} / \mathrm{LV}$ and $\mathrm{LV}$ in this test network.

Based on the investigation in [40] a defined amount of load $(9815 \mathrm{~kW})$ and installed renewable generation were randomly distributed. The main amount of RES is installed in country and suburb area and the main installed load is in the central city. Load profiles are modelled with standardized load profiles for households, business and agriculture. The installed renewable power for the VPP operation is considered to be $339.25 \mathrm{~kW}$ bio generation, $2126.56 \mathrm{~kW}$ wind generation and $7279.39 \mathrm{~kW}$ photovoltaic (pv, mainly in low voltage). The case study represents a scenario with high wind and photovoltaic infeed time-series for one day in 15 minute values and the operational starting point for bio power plants were expected to be $50 \%$ of nominal power output. Figure 5 shows the uncontrolled renewable energy infeed forecast in the VPP area.



Figure 6. Medium voltage test network to [36 - 39]

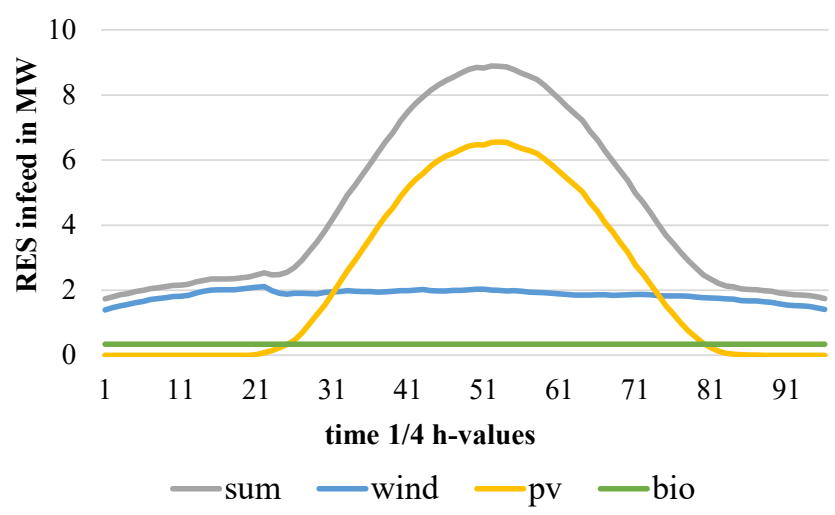

Figure 5. VPP generation day-ahead forecast

In the next step, the impact of the optimization is presented for the day-ahead planning process, with change of generation unit schedule in comparison to the uncontrolled renewable energy infeed (forecast). The test network with the implementation of load and generation as well as the according profiles offers the possibility to highlight the qualitative impact of the operational concepts on the $110 \mathrm{kV}$ hand-over point exemplary. The impacts demonstrate the need of schedules and the impact of centralized controlled RES in low voltage levels. It is assumed that minimum bid and increment for control reserve is below $0.1 \mathrm{MW}$, because the case study only considers a small part of a network. The VPP itself can operate with more installed capacity of RES that is distributed in a bigger area and fulfill CR market requirements. 
Furthermore, the technical oriented concepts will be exemplary represented by negative SCR contribution and negative redispatch contribution. Generation unit schedule is close to zero in case of maximum positive power provision for SCR and RD.



Figure 7. Active power demand of the medium voltage network with (grey) and without (orange) profit maximization

\subsection{Economical oriented operation}

The results of profit maximization are based on average prices for Day-Ahead market (blue) and Intra-Day market (green) as well as for CR participation (Figure 7). The revenue for PCR participation was assumed with $3646 € / \mathrm{MW}$ and for SCR: $357 € / \mathrm{MW}$ (pos. HT), $605 € / \mathrm{MW}$ (pos. LT), $122 € / \mathrm{MW}$ (neg. HT), $318 € / \mathrm{MW}$ (neg. LT).

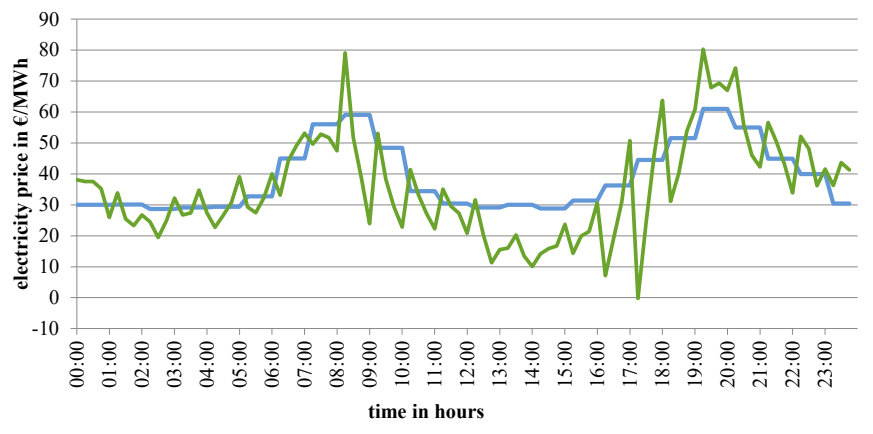

Figure 8. VPP generation unit scheduling for profit maximization



Figure 9. VPP generation unit scheduling for profit maximization
The overall expected profit for average spot-market prices of CRmarket, Day-Ahead and Intra-Day market is about $1443.24 €$. Most of the energy is planned to be traded on the Intra-Day market. Only less power is provided for positive SCR in low tariff with 1.563 MW and 2.297 MW in high tariff. The optimized generation unit schedule is reduced according to SCR provision (Figure 9).

Figure 7 demonstrate the impact of the profit maximization at the $110 \mathrm{kV}$ hand-over point before profit maximization (orange) and after (grey). Due to the CR provision, the demand in this network area increases. It can be stated that the power demand of the network section is strongly reduced during the middle of the day, caused by a high PV infeed.

\subsection{Technical oriented operation}

The schedule loyalty is one of the basic needs for future system operation with high percentage of RES. The starting point for this concept is close to profit maximization, but the capacity for flexibilities has to be defined. Therefore, the day-ahead planning process is optimizing with only $95 \%$ of forecast and a maximum of $90 \%$ for bio generation. Therefore, the day-ahead schedule is set according to Figure 10. Furthermore, a random failure of maximum $5 \%$ is assumed in each time step for wind and PV forecast. The Day-Ahead schedule expects a profit of about 1337.21 $€$, which lower compared to profit maximization. Most of the power is planned to be traded again in the Intra-Day market, but less power is provided for positive SCR in low tariff with $1.493 \mathrm{MW}$ and $2.191 \mathrm{MW}$ in high tariff.

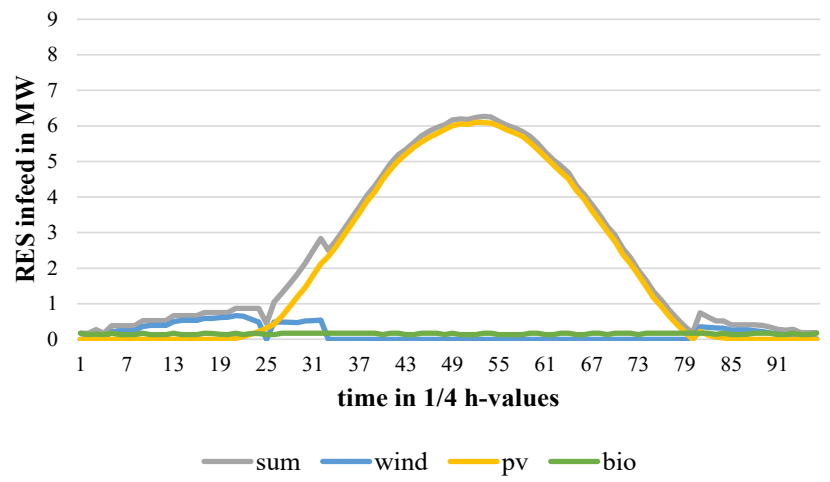

Figure 10. VPP day-ahead generation unit scheduling for schedule loyalty optimization



Figure 11. VPP intra-day deviation of generation in comparison to dayahead schedule 


\section{A. Richter et al. / Advances in Science, Technology and Engineering Systems Journal Vol. 3, No. 1, 135-147 (2018)}

The planned schedule can be fullfilled during the intra-day operation without any CR constraint violation and without any balancing power consumption. The intraday difference in generation unit operation is shown in Figure 11. The results demonstrate the functionality of this optimization concept. Furthermore, it was shown that the reduction of profit is relatively small in comparison to profit maximization, but the system benefit is enormous.

Eventually, the results for negative secondary control reserve and negative redispatch maximization are presented exemplary for all concepts of system service maximization. Both concepts represent the objective to maximize the power in within the planning horizon to provide maximum power that can be reduced by negative RD or negative SCR activation. Though results in generation unit schedule are the same, the reason of use is different. Figure 12 presents the day-ahead generation unit schedule. By considering the sum of generation, power output is maximized with repect to planned negative SCR and RD. In case of call of power reduction (RD) or negative SCR the maximum power is reduced. In particular at time step 25 , there is a small reduction of wind caused by local weather conditions. It has a high impact on the maximization because PV infeed is low in the morning and the share of bio generation is small

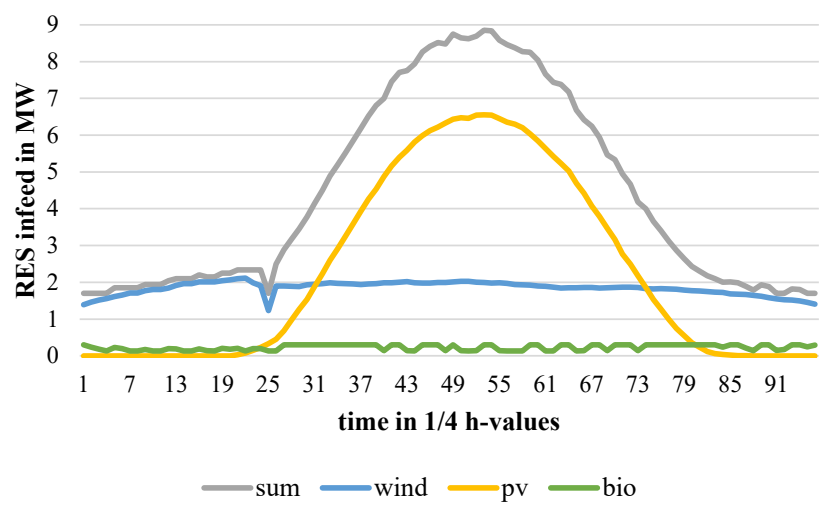

Figure 12. VPP generation unit schedule for maximization of negative SCR and negative $\mathrm{RD}$

One main challenge and requirement for these concepts is the embodiment of incentives to support the system with these functionalities. On the other hand, is the concept of intra-day schedule loyalty. Schedule loyality is one of the best circumstances for system operatores point of view in terms of high voltilty during system operation. The concept of intra-day schedule loyalty needs only small incentives to be integrated in the german power system and leads only to small losses in profit. This concept can optimally be applied with controllable, forecast independent, generation or storage units. Otherwise, with a high amount of pv and wind it is necessary to make a day-ahead schedule with reduced forecast. But in the end this concept is main requirement for future system with high amount of RES and less conventionals to keep the system stable.

Figure 13 illustrate the change of power demand of the network at $110 \mathrm{kV}$ hand-over point in case of call of negative SCR or negative RD (orange). The demand of active power before activation (grey) indicates a low load in comparison to the installed RES with times of power infeed in the $110 \mathrm{kV}$ network. The activation of SCR or $\mathrm{RD}$ can almost double the demand during the middle of the day, depending on the high PV infeed.

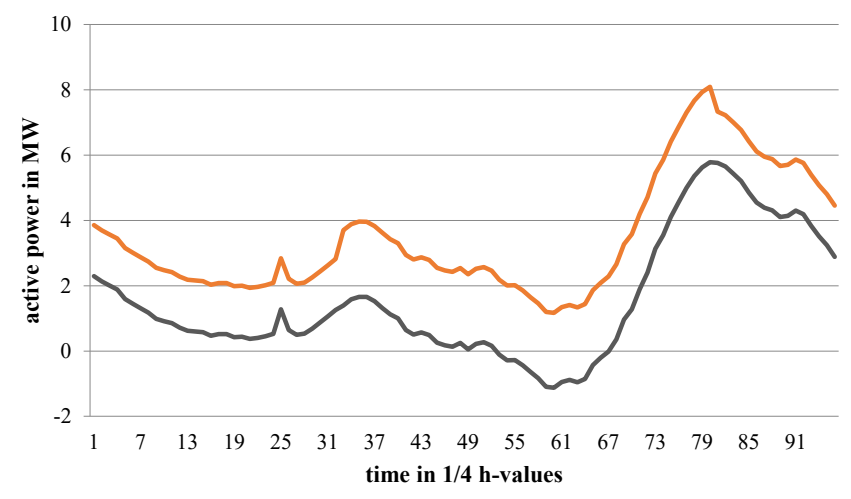

Figure 13. VPP intra-day deviation of generation in comparison to dayahead schedule

\section{Summary}

The ongoing penetration of RES, especially in lower voltage levels, lead to a dramatically lack of needed system operation control funcitionalities as well as to enourmous increase of volatile generation. Therefore, this paper adresses their synergetic use in VPPs and their operational concepts. One basic advantage is the available schedule information for the system operator due to the centralized control for a defined network area. This can immensely optimize the DSO's and TSO's planning and operation process and enable generation process interventions (active and reactive power control) by involving the VPP control center, without having expensiv direct communication excess to each small unit. On top of that, it has been shown that the technical preconditions for the implementation of VPP in Germany are provided. Several suitable communication standards that meet the requirements of an intelligent power network and its decentralized generation units are already in use.Furthermore, the profit maximization concept indicates the generation of profit under currently given market conditions and without any renewable remuneration in the case study. But this result is without regarding costs for the operation of the VPP and this concept requires a sensitivity analysis to identify the minimum optimal number and kinds of generatin units to generate profit. However, there are many technical flexibilities like active and reactive power adjustments of decentralized generation units as well as storage systems, which can partly solve the uncertainty problem of demand and volatile generation forecast in particular as well as the contribution of system services. For this purpose, the concepts of intra-day schedule loyalty, control reserve maximization and redispatch maximization have been presented. The different concepts can be used in order to improve a stable and reliable system operation today and in the future. The presented technical concepts of $\mathrm{CR}$ and RD maximization algorithms are based on the profit maximization extended by fictious profits. This leads to the advantage that the algorithms enable the definition of needed monetary incentives to fulfill technical oriented operational concepts by optimal identification of fictious prices under changing market conditions. Furthermore, the case study demonstrates the importance of the information about location of generation units and day-ahead scheduling for $\mathrm{CR}$ and $\mathrm{RD}$ 
maximization, where the call of system services can dramatically change the power demand at the hand-over point.

Eventually, the economical aspect is the most important one, especially from a VPP operator's point of view. As long as there is no sufficient level of monetary incentives, a reasonable support for the power system will not be provided. Under the given market conditions and the validity of the German Renewable Energy Act the profit for a single generation unit is much higher as for a VPP system compound, especially with regard to installation costs for a communication system and control center. Nevertheless, the future market will be dominated by renewable energy sources, so that the VPP concept will become more and more important for maintaining and improving a reliable and secure power system operation.

Limitations of the presented methods might be the computational time in case of increasing the number of constraints and by using MATLAB as the solver. For example, by defining individual technical and economical constraints for each generation unit in a VPP, the optimization complexity will increase dramatically, so that a more professional mathematical solver (e.g. Gurobi optimizer) is needed. Furthermore, the presented methods are day-ahead planning methods for a complete schedule over 96 time steps without any interruption in between two time steps. A further challenge can be to transfer the concepts of $\mathrm{CR}$ and RD into intra-day operation by taking system states of network frequency, line congestions and voltage stability into account [41], under consideration to calculate a new optimal solution for each next time step. By taking this aspects into account, the mathematical problem will rise strongly depending on the size of the network, size of VPP and the assumptions made.

\section{Conflict of Interest}

The authors declare no conflict of interest.

\section{Acknowledgment}

This paper has been worked out as part of the project "REGEES" funded by the German Federal Ministry for Economic Affairs and Energy. The authors are grateful for funding their research.

\section{References}

[1] A. Richter; N. Moskalenko, I. Hauer, T. Schröter and M. Wolter, "Technical integration of virtual power plants into German system operation", 14th International Conference on the European Energy Market (EEM): 6-9 June 2017, Dresden, Germany, DOI: 10.1109/EEM.2017.7981876

[2] Bundesministerium für Umwelt, Naturschutz, Bau und Reaktorsicherheit, Nationale Klimapolitik, http://www.bmub.bund.de/themen/klimaenergie/klimaschutz/ nationale-klimapolitik, 14.09.2015

[3] Statistisches Bundesamt, Bruttostromerzeugung 2016: $30 \%$ stammten aus erneuerbaren Energien, 2017

[4] Informationsplattform der Deutschen Übertragungsnetzbetreiber, EEGAnlagenstammdaten, Stand 31.12.2013

[5] Bundesministerium für Wirtschaft und Energie, Bausteine für die Energiewende: 7Eckpunkte für das 'Verordnungspaket Intelligente Netze', 2014

[6] PwC, Virtuelle Kraftwerke als wirkungsvolles Instrument für die Energiewende, PricewaterhouseCoopers AG (pwc), 2012

[7] B. Droste-Franke et al., Brennstoffzellen und Virtuelle Kraftwerke - Energie, umwelt- und technologiepolitische Aspekte einer effizienten Hausenergieversorgung, Springer-Verlag Berlin Heidelerg, 2009

[8] Energietechnische Gessellschaft im VDE (ETG), Smart Distribution 2020 Virtuelle Kraftwerke in Verteilungsnetzen, VDE, Frankfurt a. M., 2008
[9] Next Kraftwerke GmbH, Praxisbeispiel Virtuelles Kraftwerk: Flexibilität aus erneuerbaren Energien und Industrieprozessen, 2014

[10] Deutsche Windguard, Kostensituation der Windenergie an Land in Deutschland, Varel, Dezember 2015

[11] Fraunhofer ISE, Aktuelle Fakten zur Photovoltaik in Deutschland, Freiburg, Fassung vom 22.04.2016

[12] Fraunhofer ISE, Stromgestehungskosten Erneuerbare Energien, Freiburg, November 2013

[13] B.M. Buchholz, C. Brunner, A. Naumann and A. Styczynski, "Applying IEC standards for communication and data management as the backbone of smart distribution", Power and Energy Society General Meeting, 2012 IEEE, 10.1109/PESGM.2012.6345011

[14] CEN/CENELEC/ETSI Joint Working Group, Standards for Smart Grids, Final Report, 2011

[15] Dilan Sahin, et al., Smart Grid Technologies: Communication 1st ELECON Workshop 41 Technologies and Standards Transactions on Industrial Informatics, vol. 7, no. 4, pp. 529-540, November 2011.

[16] International Electrtechnical Commission (IEC), Electropedia: the World's Online Electrotechnical Vocabulary, http://www.electropedia.org/

[17] BDEW (Bundesverband der Energie und Wasserwirtschaft) and ZVEI (Zentralverband Elektrotechnik- und Elektroindustrie e.V.), Smart Grids in Deutschland - Handlungsfelder für Verteilnetzbetreiber auf dem Weg zu intelligenten Netzen, 2012

[18] M. Richter, "PMU-basierte Zustandsabschätzung in Smart Distribution", Dissertation, Otto-von-Guericke-Universität Magdeburg, Germany, 2016

[19] N. Moskalenko, "Optimal Dynamic Energy Management Systems in Smart homes", MaFo, vol. 59, ISBN 978-3-944722-16-0, Magdeburg, 2014

[20] A. Naumann, "Leitwarte im Smart Grid", MaFo, vol. 47, ISBN 978-3940961-81-5, Magdeburg, 2012

[21] Wen-Yeau Chang, "A Literature Review of Wind Forecasting Methods", Journal of Power and Energy Engineering, 2013

[22] C. Skittides and W-G. Früh, "Wind forecasting using Principal Component Analysis", Journal Elsevier, Edinburgh, 2014

[23] Aoife M. Foley et al., "Current methods and advances in forecasting of wind power generation", Journal Elsevier, 2011

[24] National Renewable Energy Laboratory (NREL), Solar and Wind Forecasting, http://www.nrel.gov/electricity/transmission/resource forecasting.html, 2015

[25] International Energy Agency (IEA), Photovoltaic and Solar Forecasting: State of the Art, Report IEA PVPS, Canada, 2013

[26] Next Kraftwerke GmbH: Strommarkt, [Online], Available: https://www.nextkraftwerke.de/wissen/strommarkt.

[27] Tariq Kamal, Syed Zulqadar Hassan, Muhammad Hussnain Riaz, Hui Li, Muhammad Sarmad and Gussan Maaz Mufti, "Design and Control of Photovoltaic/Microturbine/Super-Capacitor based Microgrid System", 20th IEEE International Multitopic Conference 2017 (INMIC 2017) at National University of Computer and Emerging Sciences (FAST-NUCES) Lahore campus, Pakistan from November 24-26, 2017.

[28] European Energy Exchange AG (EEX), EEX Produktbroschüre Strom, 2012. [Online]. Available: http://eex.com/blob/66450/6aee0902c1 f341968d1flb948f3b1a5b/konzeptstrom-release-03a-deutsch-pdf-data.pdf.

[29] P. Konstantin, Praxisbuch Energiewirtschaft, 3 Hrsg., Berlin, Heidelberg: Springer Vieweg, 2013

[30] EPEX SPOT SE. Price List: Valid as of 1st January 2016. https://www.epexspot.com/document/34180/EPEX\%20SPOT_Price\%20List \%20January\%202016.pdf

[31] 4 German TSO, Market for control reserve in Germany, [Online] Available: https://www.regelleistung.net/ext/static/market-information

[32] 4 German TSO, About control reserve and Tender details, [Online] Available: https://www.regelleistung.net/ext/

[33] Bundesnetzagentur, Bundesnetzagentur verbessert die Bedingungen zur Teilnahme an den Regelenergiemärkten Strom, Press announcement, 28.06.2017

[34] W. Domschke, Einführung ins Operation Research. 9. Auflage, Berlin: Springer-Verlag, 2015

[35] M. Tröschel, "Aktive Einsatzplanung in holonischen virtuellen Kraftwerken", Dissertation, 2010

[36] CIGRE Task Force C6.04, Benchmark Systems for Network Integration of Renewable and Distributed Energy Resources, ISBN: 978-285-873-270-8, 2013

[37] Netzentwicklungsplan Strom 2025, Version 2015: Zweiterer Entwurf der Übertragungsnetzbetreiber, Feb. 2016, [Online]. Available: http://www.netzentwicklungsplan.de/ _NEP_file_transfer/NEP_2025_2_Entwurf_Teill.pdf 
[38] Thüringer Energie- und GreenTech-Agentur, Studie zu lokalen Energiespeicherbedarfen: Analyse und Prognose der Technologien und Anwendungsfelder thermischer und elektrischer Energiespeicher auf Niederund Mittelspannungsebene, Juni 2014, Erfurt

[39] BMWi, Studie: Moderne Verteilernetze für Deutschland, Abschlussbericht, September 2014

[40] A. Richter, Chr. Ziegler, N. Moskalenko and M. Wolter, Das Virtuelle Kraftwerk als gewinnorientierter Akteur mit verteilnetzunterstützendem Potential, im Tagungsband 4. Konferenz Zukünftige Stromnetze für Erneuerbare Energien, Berlin, Germany, 2017

[41] D.P. Kothari and J. S. Dhillon, Power System Optimization, Prentice-Hall of India, 2004, 2nd Edition, 2011 